\title{
Evaluation of the quality of life related to health in adolescent patients with epilepsy through the application of the scale quality of life impact in epilepsy adolescents
}

\author{
Judmila López-Sánchez¹, Eduardo Barragán-Pérez², Alejandra Castañón-González ${ }^{3}$ and \\ Julio C. López-Valdés ${ }^{4,5 *}$
}

${ }^{1}$ High Specialty, "Dr. Rodolfo Nieto Padrón" Hospital, Villahermosa, Tabasco; " "Federico Gómez" Children's Hospital of Mexico, Mexico City; ${ }^{3}$ High Specialty Medical Unit, "Dr. Silvestre Frenk Freund," Pediatric Hospital, National Medical Center "Siglo XXI", Instituto Mexicano del Seguro Social (I.M.S.S.), Mexico City; ; Research Department, School of Medicine of Tamaulipas “Dr. Alberto Romo Caballero,"Autonomous University of Tamaulipas, Tampico, Tamaulipas; ${ }^{5}$ Cognitive Science S.A., Mexico City. Mexico

\begin{abstract}
Introduction: Epilepsy is a chronic disease that affects the quality of life $(Q 0 L)$ of adolescent patients. The objective of the study was to determine the QoL related to health in adolescent patients with epilepsy treated at the Federico Gómez Children's Hospital of Mexico using the QoL impact in epilepsy adolescents (QOLIE-AD-48) scale application. Materials and methods: An observational, descriptive, and transversal study was carried out. Adolescent patients with a diagnosis of epilepsy and specific characteristics obtained by non-random convenience were evaluated. A questionnaire with socio-demographic data and the QOLIE-AD-48 questionnaire were applied. Results: We obtained 35 participants, 51.5\% male, with an average age of 14.2 years \pm 1.4 (standard deviation), the average duration of 4.7 years. Regarding schooling, $13 \%$ of participants have failed a grade level. About $11.4 \%$ do not attend school. Epileptic seizures were classified as focal (71.4\%) and generalized (28.6\%). The largest number of cases was in monotherapy in $68.6 \%$, and the most common drugs are valproic acid (39.4\%) and levetiracetam (27.3\%). The QOLIE-AD-48 score was 65.20. The most affected domains, according to gender were: attitude toward epilepsy and physical functioning, for female and male, respectively. Overall, the lowest scores are attitudes toward epilepsy and health perception. Conclusions: Despite adequate control of seizures, the QoL related to the health of adolescents with epilepsy is regular. This suggests that not only the crisis and the number of them influence the external environment of adolescents but also that other factors can be included in the overall well-being.
\end{abstract}

Key words: Quality of life related to health. Epilepsy. Adolescence. Quality of life.

\section{Introduction}

Epilepsy is a non-communicable chronic disorder which affects people of all ages. Worldwide, calculations suggest that $1.5-2 \%$ of teenagers have epilepsy ${ }^{1}$. It is important to mention that epilepsy during adolescence requires special attention, since its diagnosis triggers psychological and social problems, giving rise to significant changes in the life of the individual and his/her family, resulting in a decrease in quality of life (QoL) $)^{2,3}$.

The World Health Organization defines the concept of QoL as "the perception of an individual of his condition in life, culturally and the value system in which the individual lives, regarding their goals, objectives, expectations, values, and concerns ${ }^{\prime \prime 4}, 5$. In addition, health-related

\section{Correspondence:}

*Julio C. López-Valdés

E-mail: jc.lopz@live.com
Available online: 09-08-2019

Date of reception: 27-01-2019

Date of acceptance: 19-03-2019 DOI: 10.24875/RMU.19000052
Medicina Universitaria. 2019;21(2):40-50 www.medicinauniversitaria.org

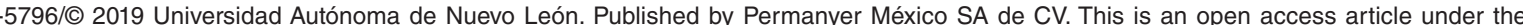
CC BY-NC-ND license (http://creativecommons.org/licenses/by-nc-nd/4.0/). 
QoL (HRQoL) is a multidimensional construct which describes physical, psychological, and social well-being. It focuses on the satisfaction or happiness of an individual, and the way these aspects are affected by illness. HRQoL can be affected by the presence of an illness, especially a chronic one, such as with epilepsy, due to the implications inherent to this disease ${ }^{5}$. While the prognosis can be estimated through the information provided by close relatives, as well as clinical observation, the use of specific scales to measure QoL indicators becomes necessary, hence giving the potential impact of chronic diseases objectivity, specifically epilepsy.

There have been several studies linked to QoL in different countries, using standardized scales and which are generally adapted to a specific disease and other factors, such as the patient's age and local circumstances.

The first QoL scales in epilepsy were mainly oriented toward assessing functional and physical parameters; subsequently, other characteristics were added, such as psychological and social variables. One of the first ones to be implemented was the QoL in Childhood Epilepsy Questionnaire. In the following years, a variety of instruments began to emerge, created with the sole intention of measuring variables at different levels, beyond physical status. Among them, we can mention the impact of pediatric epilepsy scale elaborated in Canada $^{6}$, and the QoL impact in epilepsy adolescents (QOLIE-AD-48) 5 .

The introduction of these instruments is not only limited to the research of therapeutic clinical trials but it also helps in the creation of decision-making models which help us solve problems specific to this population, such as health cost problems and allocation of resources ${ }^{4}$.

In Mexico, there is a limited if not non-existent number of articles regarding QoL in patients with epilepsy. While in prior years, Lopez-Rojas et al. ${ }^{7}$ conducted a study using the QOLIE-31 questionnaire in a third-level hospital for the evaluation of QoL in pediatric patients of a similar age group, it is necessary to stress the fact that said instrument is only recommended for adults (18 and older) with epilepsy ${ }^{8}$. Therefore, there is a need to expand the analysis through an upgrade of the QOLIE-AD-48, designed specifically for adolescents ${ }^{5}$.

The objective of this study was to determine the QoL linked to health in adolescent patients with epilepsy who were treated at the "Federico Gómez" Children's Hospital of Mexico through the application of the QOLIE-AD-48; additionally, and if possible, to determine the socio-demographic characteristics of this population and their influence over this disease.

\section{Materials and methods}

\section{Design of the study and sample}

An observational, prospective, longitudinal study was conducted from January 1, 2016, to May 31, 2016. The use of a population by convenience was determined, including patients who attended the Neurology Outpatient Clinic of the "Federico Gómez" Children's Hospital of Mexico, which is a third-level government hospital unit located in Mexico City. Hence, it has a high volume of patients coming from all over the country. For practicality, epileptic crises are classified based on the International League against Epilepsy (ILAE) from 1981 as focal and generalized.

The study included both male and female patients, between the ages of 12 and 17 years and 11 months, integrated into society, capable of reading Spanish, and with a documented diagnosis of active epilepsy (at least one seizure in the past 6 months), from any etiology. Moreover, for this study, patients with intellectual impairment were excluded, as well as patients with psychotic pictures, as well as those who had undergone brain surgery in the last year and other chronic concomitant diseases which directly affected QoL (i.e., alcoholism, drug abuse, chronic renal failure)

\section{Data recollection technique}

Socio-demographic data were obtained, such as gender, age, time of diagnosis, evolution time of the disease and its etiological cause, type of epilepsy, and therapy employed. Data collection was performed manually, daily, with a subsequent review of the proper filling out of each of the instruments, and finally, electronically captured in a spreadsheet using Microsoft Office $2016^{\text {TM }}$.

After initial assessment and data recollection, the QOLIE-AD-48 questionnaire was conducted. It is worth noting that the Spanish version of this questionnaire is an individual, self-applicable instrument previously validated by Benavente-Aguilar et al. ${ }^{9,10}$ In addition, just as in the original version, it has proven to have trustworthy psychometric properties and validity.

The questionnaire has 48 individual questions in eight domains distributed into different sections, which are evaluated as follows:

1. Impact of the epilepsy - 12 items (questions 25-27, 29-34, 36, 47, and 48)

2. Memory and concentration - 10 items (questions 8 , 12-20)

3. Attitude toward epilepsy - 4 items (questions 43-46) 
4. Physical functioning -5 items (questions 3-7)

5. Stigma - 6 items (questions 37-42)

6. Social support -4 items (questions 21-24)

7. Behavior at school -4 items (questions 9-11 and 27)

8. Perception of health -3 items (questions 1,2 , and 35).

The score obtained in the questionnaire is converted to a scale from 0 to 100 points, with the help of tables and mathematical operations previously designed for this questionnaire. The sum of the scores in each area provides the global score, which indirectly reflects the patient's QoL. High scores always indicate a better QoL. The values for these points are divided as follows:

- 91-100: excellent QoL.

- 81-90: very good QoL.

- 71-80: good QoL.

- 61-70: a regular QoL.

- Less or equal to 60: bad QoL.

\section{Statistical analysis}

The data obtained were analyzed using Microsoft's Excel $^{\text {TM }}$, from Microsoft Office 2016 ${ }^{\text {TM }}$, using descriptive statistics for the exposition of demographic data. The results obtained are shown in means and standard deviation (SD) when the variables are quantitative, and in percentages when qualitative.

\section{Results}

A total of 35 patients with a documented diagnosis of epilepsy were obtained. The average age was 14.2 \pm 1.4 (SD) years, with a fairly equal gender distribution, yet with a slight male predominance (51.5\%). The average age for the onset of epilepsy was $8.9 \pm 4.6$ (SD) years old, with an average evolution of the disease of $4.7( \pm S D)$ years. Additional socio-demographic data are listed in Table 1.

\section{Factors linked to alterations of QoL}

When evaluating the level of education, $88.6 \%$ of the participants had some formal education, and only 4 participants were found to be without any educational background. Moreover, from the 31 patients who attended school, $13 \%$ had failed or missed a school year, all of them male. Out of this group of patients with failed school years, $50 \%$ presented at least one seizure a day, $75 \%$ were found to be in management with polypharmacy, mainly with valproic acid and topiramate. The rest of the data is shown in table 2 .
Focal epileptic seizures occurred in $71.4 \%$ of the participants. There was a predominance of focal seizures secondarily generalized (44\%). On the other hand, $40 \%$ of the cases corresponded to a focal crisis with alteration in alertness, and only $16 \%$ were considered simple focal seizures. In general seizures, half of the cases were tonic-clonic.

The distribution according to the etiology of epilepsy within the group was as follows: About $48.6 \%$ symptomatic (17 cases), followed by idiopathic causes with $34.3 \%$, and cryptogenic causes, which only represented $17.1 \%$. Complete results of the symptomatic causes are close to the MRI reports, where findings showed that 13 of the participants in this study (37.1\%) had alterations.

Most patients $(63 \%)$ reported one or zero seizures a year. For the rest of the participants, patterns went from 1 seizure per month (17.1\%) to 1 seizure per day (11.4\%) and 1 seizure per week (8.6\%). Reports show that females had better control over their seizures $(70.6 \%$ with $\leq 1$ seizure/year), while in males the pattern was $\leq 1$ seizure/year in $55.5 \%$.

Regarding received antiepileptic pharmacotherapy, findings show that the majority of patients were being treated through a regime based on monotherapy (68.6\%). Among the 33 participants, the most prominent pharmaceutical was valproic acid with $39.4 \%$ followed by levetiracetam with $27.3 \%$. It is important to note that these numbers were only determined by the frequency with which the pharmaceutical was registered in the current treatment of the patient according to the recollection sheet; however, medication combinations are not described in this paper, nor is their effectiveness.

\section{Subscales linked to the QoL of the adolescent patient with epilepsy}

Once we applied the QOLIE-AD-48 scale, we were able to obtain an average of the subscales/domains of 63.38. The affection is more significant in females, with a score of 60.91, versus that reported in males, which were 65.76 .

The predominant domains for each gender significantly differ from one another. The areas with the best score for females were the impact of epilepsy and behavior at school. On the other hand, in males, the areas of social stigma and social support stand out (Fig. 1).

\section{Discussion}

In this study, demographic factors linked to the QoL in adolescent patients with an epilepsy diagnosis were 
Table 1. Demographic characteristics of the population. Value of significance 0.5

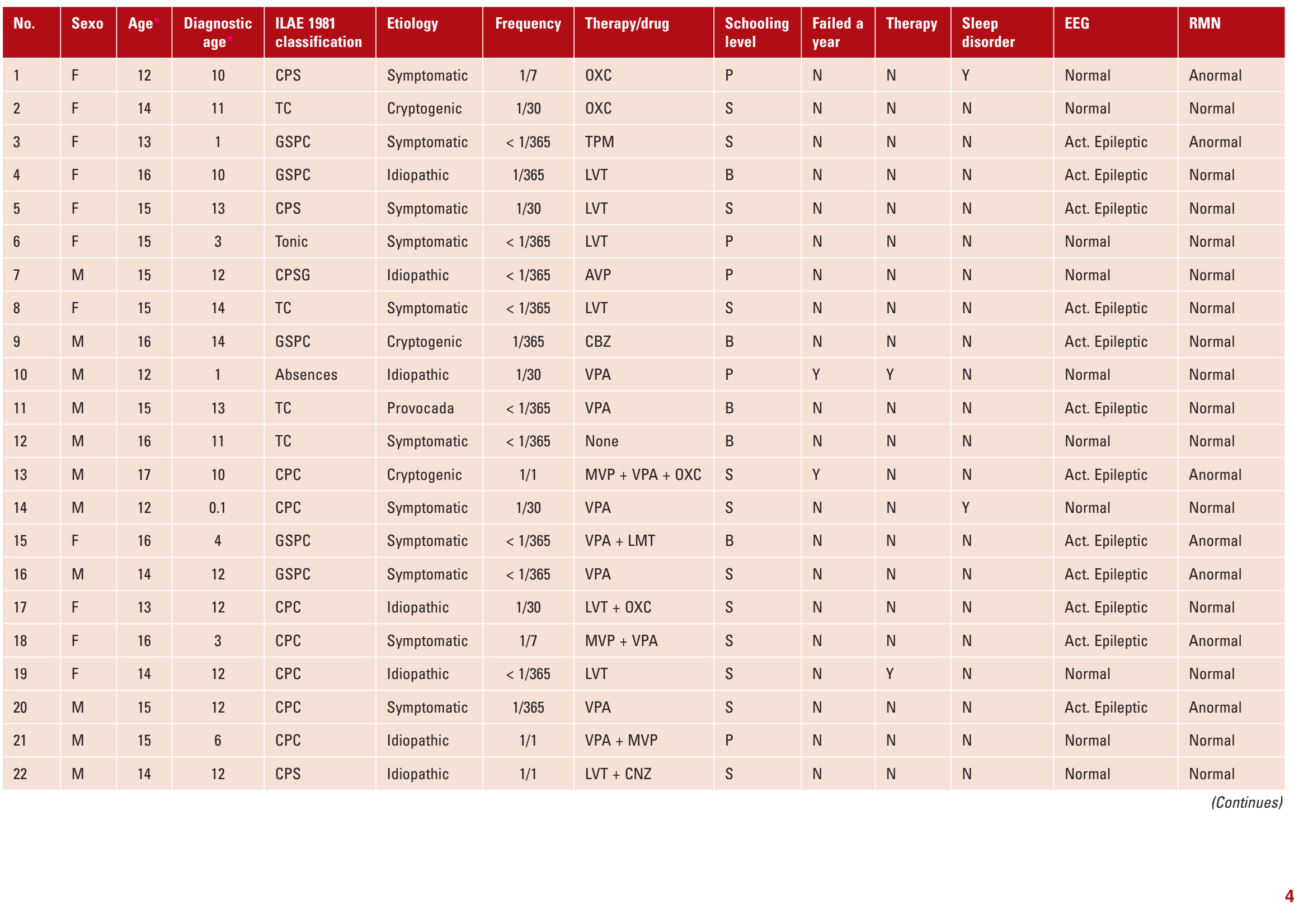


Table 1. Demographic characteristics of the population (Continued)

\begin{tabular}{|c|c|c|c|c|c|c|c|c|c|c|c|c|c|c|}
\hline No. & Sexo & Age & $\begin{array}{l}\text { Diagnostic } \\
\text { age }\end{array}$ & $\begin{array}{l}\text { ILAE } 1981 \\
\text { classification }\end{array}$ & Etiology & Frequency & Therapy/drug & $\begin{array}{l}\text { Schooling } \\
\text { level }\end{array}$ & $\begin{array}{l}\text { Failed a } \\
\text { year }\end{array}$ & Therapy & $\begin{array}{l}\text { Sleep } \\
\text { disorder }\end{array}$ & & EEG & RMN \\
\hline 23 & $\mathrm{~F}$ & 13 & 3 & CPC & Symptomatic & $<1 / 365$ & VPA & S & $\mathrm{N}$ & $Y$ & $\mathrm{~N}$ & $\frac{\xi}{0}$ & Act. Epileptic & Anormal \\
\hline 24 & $\mathrm{~F}$ & 14 & 13 & GSPC & Symptomatic & $<1 / 365$ & $V P A+L V T$ & $S$ & $\mathrm{~N}$ & $Y$ & $\mathrm{~N}$ & (ब) & Normal & Anormal \\
\hline 25 & M & 14 & 3 & Atonic & Cryptogenic & $1 / 1$ & LVT + MVP + PRM & $P$ & Y & Y & Y & 这 & Act. Epileptic & Normal \\
\hline 26 & $\mathrm{~F}$ & 15 & 10 & $\mathrm{CPC}$ & Symptomatic & $1 / 365$ & VPM & B & N & N & N & 言 & Act. Epileptic & Anormal \\
\hline 27 & M & 15 & 14 & TC & Symptomatic & $<1 / 365$ & LVT & $S$ & N & N & $\mathrm{N}$ & $\stackrel{\Perp}{\ddagger}$ & Act. Epileptic & Anormal \\
\hline 28 & $\mathrm{~F}$ & 17 & 16 & Tonic & Symptomatic & $<1 / 365$ & None & B & N & $\mathrm{N}$ & $\mathrm{N}$ & ¿ & Normal & Normal \\
\hline 29 & $M$ & 12 & 0.4 & GSPC & Cryptogenic & $1 / 7$ & $T P M+O X C$ & $P$ & Y & $\mathrm{N}$ & $Y$ & है & Act. Epileptic & Normal \\
\hline 30 & $M$ & 13 & 11 & GSPC & Symptomatic & $<1 / 365$ & VPM & $S$ & N & $Y$ & $\mathrm{~N}$ & $\begin{array}{l}0 \\
\frac{c}{0}\end{array}$ & Act. Epileptic & Anormal \\
\hline 31 & M & 15 & 11 & CPC & Idiopathic & $1 / 30$ & $\mathrm{CBZ}$ & $S$ & $N$ & N & $N$ & $\frac{5}{3}$ & Normal & Normal \\
\hline 32 & $F$ & 12 & 5 & GSPC & Cryptogenic & $<1 / 365$ & CBZ & $P$ & $\mathrm{~N}$ & N & $\mathrm{N}$ & 히 & Normal & Normal \\
\hline 33 & $M$ & 12 & 11 & Tonic & Idiopathic & $1 / 365$ & $\mathrm{CBZ}$ & $S$ & $\mathrm{~N}$ & N & $\mathrm{N}$ & 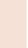 & Normal & Normal \\
\hline 34 & $\mathrm{M}$ & 12 & 11 & CPS & Idiopathic & $<1 / 365$ & OXC & $P$ & $\mathrm{~N}$ & N & $Y$ & F & Act. Epileptic & Normal \\
\hline 35 & $\mathrm{~F}$ & 14 & 10 & CPC & Idiopathic & $<1 / 365$ & MVP & S & $\mathrm{N}$ & $\mathrm{N}$ & $\mathrm{N}$ & 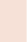 & Normal & Normal \\
\hline
\end{tabular}

SPC: simple partial crisis; TC: tonic-clonic; GSPC: generalized simple partial crisis; CPC: complex partial crisis; OXC: oxcarbazepine; TPM: topiramate; LVT: levetiracetam; VPA: valproic acid; CBZ: carbamâzepine; LMT: lamotrigine; CNZ: clonazepam; PRM: primidone; MVP: magnesium valproate; P: primary; S: secondary; B: bachelor's, Y: yes; N: no; ILAE: International League against Epilepsy. 
Table 2. Clinical characterization of adolescents diagnosed with epilepsy

\begin{tabular}{|c|c|c|c|}
\hline Variable & Total $(\mathrm{n}=35)$ & Men ( $n=18)$ & Women $(\mathrm{n}=17)$ \\
\hline Age (average \pm SD) & $14.2 \pm 1.4$ (years) & $14.11 \pm 1.60$ (years) & $14.35 \pm 1.32$ (years) \\
\hline Diagnostic age (average \pm SD) & $8.98 \pm 4.63$ (years) & $9.14 \pm 4.76$ (years) & $8.82 \pm 4.63$ (years) \\
\hline Time of evolution & $5.24 \pm 4.27$ (years) & $4.97 \pm 4.09$ (years) & $5.53 \pm 4.55$ (years) \\
\hline $\begin{array}{l}\text { Scholastics } \\
\text { Primary } \\
\text { Secondary } \\
\text { Middle-high school } \\
\text { No formal education }\end{array}$ & $\begin{array}{c}7(20 \%) \\
17(48.57 \%) \\
7(20 \%) \\
4(11.43 \%)\end{array}$ & $\begin{array}{c}5(71.43 \%) \\
7(41.18 \%) \\
3(42.86 \%) \\
3(75 \%)\end{array}$ & $\begin{array}{c}2(28.57 \%) \\
10(58.82 \%) \\
4(57.14 \%) \\
1(25 \%)\end{array}$ \\
\hline $\begin{array}{l}\text { Etiology } \\
\text { Symptomatic } \\
\text { Cryptogenic } \\
\text { Idiopathic } \\
\text { Provoked }\end{array}$ & $\begin{array}{c}16(45.72 \%) \\
6(17.14 \%) \\
12(34.28 \%) \\
1(2.86 \%)\end{array}$ & $\begin{array}{c}7(43.75 \%) \\
4(66.67 \%) \\
6(50 \%) \\
1(100 \%)\end{array}$ & $\begin{array}{c}9(56.25 \%) \\
2(33.33 \%) \\
6(50 \%) \\
0(0 \%)\end{array}$ \\
\hline $\begin{array}{l}\text { Crisis type } \\
\text { Focal epileptic seizures } \\
\text { Simple partials } \\
\text { Partially generalized partial } \\
\text { Complex partials } \\
\text { Generalized seizures } \\
\text { Tonic-clonic } \\
\text { Tonic } \\
\text { Atonic } \\
\text { Absence }\end{array}$ & $\begin{array}{c}25(71.43 \%) \\
4(11.43 \%) \\
11(31.43 \%) \\
10(28.57 \%) \\
10(28.57 \%) \\
5(14.28 \%) \\
3(8.57 \%) \\
1(2.86 \%) \\
1(2.86 \%)\end{array}$ & $\begin{array}{c}10(40 \%) \\
2(50 \%) \\
4(36.36 \%) \\
4(40 \%) \\
8(80 \%) \\
4(80 \%) \\
2(66.67 \%) \\
1(100 \%) \\
1(100 \%)\end{array}$ & $\begin{array}{c}15(60 \%) \\
2(50 \%) \\
7(63.64 \%) \\
6(60 \%) \\
2(20 \%) \\
1(20 \%) \\
1(33.33 \%) \\
0 \\
0\end{array}$ \\
\hline $\begin{array}{l}\text { Seizure frequency } \\
<\text { Once a month } \\
\geq \text { Once a month }\end{array}$ & $\begin{array}{l}22(62.86 \%) \\
13(37.14 \%)\end{array}$ & $\begin{array}{c}10(45.45 \%) \\
8(61.54 \%)\end{array}$ & $\begin{array}{c}12(54.55 \%) \\
5(38.46 \%)\end{array}$ \\
\hline $\begin{array}{l}\text { Number of antiepileptic drugs } \\
\text { Monotherapy } \\
\text { Polytherapy } \\
\text { No treatment }\end{array}$ & $\begin{array}{c}24 \\
9 \\
2\end{array}$ & $\begin{array}{c}12(50 \%) \\
5(55.56 \%) \\
1(50 \%)\end{array}$ & $\begin{array}{c}12(50 \%) \\
4(45.44 \%) \\
1(50 \%)\end{array}$ \\
\hline $\begin{array}{l}\text { Drugs used } \\
\text { Oxcarbazepine } \\
\text { Levetiracetam } \\
\text { Topiramate } \\
\text { Valproic acid } \\
\text { Magnesium valproate } \\
\text { Carbamazepine } \\
\text { Primidone } \\
\text { Clonazepam } \\
\text { Lamotrigine }\end{array}$ & $\begin{array}{c}6(17.14 \%) \\
10(28.57 \%) \\
6(17.14 \%) \\
10(28.57 \%) \\
3(8.57 \%) \\
4(11.43 \%) \\
1(2.85 \%) \\
1(2.85 \%) \\
1(2.85 \%)\end{array}$ & $\begin{array}{c}3(50 \%) \\
3(30 \%) \\
4(66.66 \%) \\
6(60 \%) \\
1(33.34 \%) \\
3(75 \%) \\
1(100 \%) \\
1(100 \%) \\
0\end{array}$ & $\begin{array}{c}3(50 \%) \\
7(70 \%) \\
2(33.34 \%) \\
4(40 \%) \\
2(66.66 \%) \\
1(25 \%) \\
0 \\
0 \\
1(100 \%)\end{array}$ \\
\hline
\end{tabular}

analyzed, obtaining similar results to previous studies through the QoLIE-48 questionnaire (Table 3) ${ }^{11-20}$.

A male predominance was found ${ }^{11-20}$. However, females were reported as more susceptible to the psychosocial strains caused by the disease. Thus, females suffered greater auto-anxiety, lower self-happiness, and more negative attitudes toward their condition compared to males ${ }^{21}$. This concurs with the data documented through the "Latin American Epilepsy Report," where the need to give women with epilepsy proper holistic medical attention were reported, one that goes beyond simple control of seizures ${ }^{22,23}$.
In a study conducted by Devinsky et al. ${ }^{21}$ into factors of an incorrect prognosis of HRQL in adolescents with epilepsy, the areas which were significantly affected were the attitude toward epilepsy and perception of health, creating a worse HRQL. Similarly, Austin et al. ${ }^{24}$ found more problems in the QoL among females compared to adolescent males. These problems included anxiety, unhappiness, attitude, poor relationships with their classmates, and social problems.

Our results concur with the description above since when we make a distinction between genders for each of the domains, the lower observed scores for this 


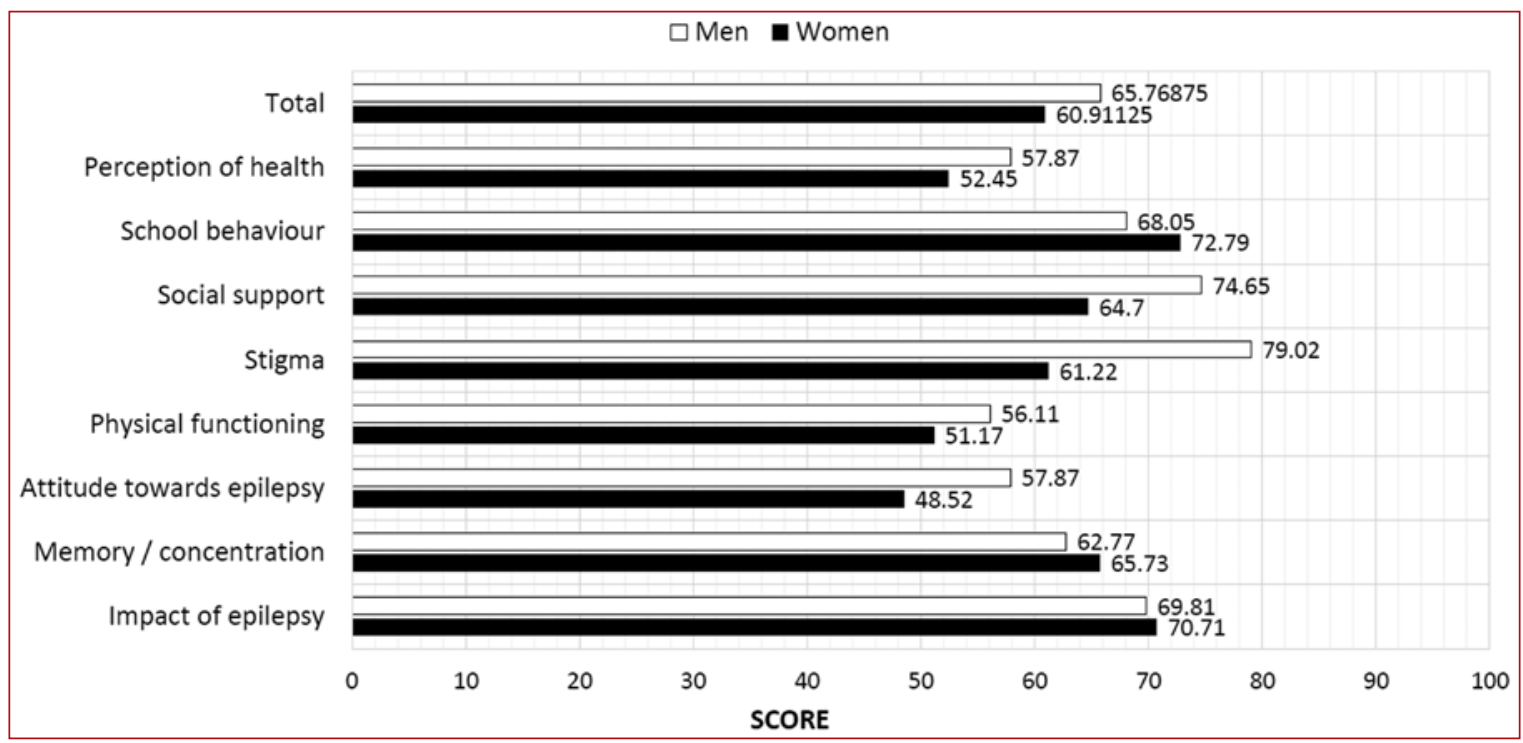

Figure 1. Comparative graph between both sexes for the results obtained from the application of the quality of life impact in epilepsy - 48 Spanish version questionnaires.

group are specifically those domains previously mentioned. Moreover, $50 \%$ of the participants had both areas affected during evaluation ${ }^{25}$.

Although age did not have a significant correlation with QoL in epilepsy, it is important to remember that adolescence is characterized by being a stage of transition involving different conducts which may interfere in the proper management of the disease ${ }^{26}$. Previous epidemiologic data have proven that the age of onset of epilepsy can have a significant association with the QoL of the patients, because early onset epilepsy can lead to a significant delay in development as a consequence of the presence of frequent seizures during the formative years, or as a result of the adverse effects of medication during times of social and cognitive development ${ }^{27}$.

Within this study, $13 \%$ of the analyzed population had to miss some portion of the school year; this could be linked to the presence of learning disorders. It is worth noting that according to Jackson et al. ${ }^{28}$, academic problems are evident in up to $50 \%$ of epilepsy cases.

Different types of learning problems in children with epilepsy are described in the literature, not only as a consequence of failure in the cognitive sphere but also secondary to lack of attention, memory or language disorders, to name a few ${ }^{29}$. Battistini et al. ${ }^{30}$ found a greater incidence of disorders specific to learning in $87 \%$ of the cases of patients with epilepsy.

Regarding the "frequency of seizures" factor, there is evidence of a decrease in cognitive capacity parallel to an increase in the frequency of the events. Moreover, it has an accumulative adverse effect ${ }^{31}$. Similarly, the effects of pharmaceutics, already noted by Lennox ${ }^{32}$, on cognitive functions, have been the object of numerous studies in the past 30 years. These effects depend on the medication, the dosage, and associations with other medications (polytherapy). In addition, not only can it generate learning disorders but also school absence and emotional disorders, among other things ${ }^{33,34}$.

The clinical presentation of epilepsy is another important factor. About $75 \%$ of the participants of this study presented seizures with focal characteristics; these being results similar to those obtained in studies of the QoL of adolescents in different countries ${ }^{35,36}$.

Even though the ILAE-1981 criteria were used, epidemiological data inherent to epileptic seizures is discordant concerning previous publications. There are evident differences concerning the etiology of our study. Almost half of the participants began with seizures of a symptomatic etiology without presenting differences according to gender. Available studies show the influence of the etiology in the prognosis of epilepsy ${ }^{37}$; this association is evident concerning seizures symptomatic to neurological alterations or birth defects, not so much when other causes of symptomatic seizures are taken into consideration.

Complete control of seizures has been considered as one of the main determinants in QoL; however, the absence of seizures, or a reduction, must not be sought for at all costs, especially when the adverse effects of 
Table 3. Comparison of the results obtained for the quality of life of adolescents with epilepsy in different countries among the population using the $00 \mathrm{LIE-AD-48}$ questionnaire

\begin{tabular}{|c|c|c|c|c|c|c|c|c|c|c|}
\hline $\begin{array}{l}\text { Variable } \\
\text { study }\end{array}$ & $\begin{array}{l}\text { López-Sánchez } \\
\text { et al. Mexico, } \\
2018(n=35)\end{array}$ & $\begin{array}{c}\text { Siqueira et al. }{ }^{14} \\
\text { Brazil, } \\
2014(n=50)\end{array}$ & $\begin{array}{c}\text { Zamani et al. }{ }^{15} \\
\text { Iran, } \\
2014(n=197)\end{array}$ & $\begin{array}{c}\text { Wu et al. } .^{12} \\
\text { China, } \\
2010(n=47)\end{array}$ & $\begin{array}{c}\text { Wang et al. }{ }^{20} \\
\text { China, } \\
2009(n=99)\end{array}$ & $\begin{array}{c}\text { Barbosa et al. }{ }^{19} \\
\text { Brazil, } \\
2008(n=93)\end{array}$ & $\begin{array}{c}\text { Stenovanovic } \\
\text { et al. }{ }^{17} \\
\text { Serbia, } \\
2005(n=67)\end{array}$ & $\begin{array}{c}\text { Benavente et al. }{ }^{9} \\
\text { Spain, } \\
2004(n=66)\end{array}$ & $\begin{array}{l}\text { Benavente } \\
\text { et al. }{ }^{10} \text { Spain, } \\
2002(n=54)\end{array}$ & $\begin{array}{c}\text { Cramer } \\
\text { et al. } .^{25} \text { United } \\
\text { Kingdom, } \\
1999(n=97)\end{array}$ \\
\hline $\begin{array}{l}\text { Impact of } \\
\text { epilepsy }\end{array}$ & 70.25 & 75.29 & 68.9 & 70.1 & 70.9 & 74.4 & 83.2 & 92.3 & 91.2 & 70.6 \\
\hline $\begin{array}{l}\text { Memory/ } \\
\text { concentration }\end{array}$ & 64.2 & 66.60 & 65.1 & 66.1 & 74.4 & 69.6 & 78 & 76 & 75.2 & 67.6 \\
\hline $\begin{array}{l}\text { Attitude } \\
\text { towards } \\
\text { epilepsy }\end{array}$ & 53.3 & 35.00 & 22.56 & 69.2 & 24.1 & 39.3 & 75.4 & 35.6 & 34.1 & 39.8 \\
\hline $\begin{array}{l}\text { Physical } \\
\text { functioning }\end{array}$ & 53.7 & 85.20 & 70.37 & 67.1 & 81 & 76.1 & 90 & 94.8 & 94.0 & 63.6 \\
\hline Stigma & 70.3 & 64.69 & 52.55 & 62.9 & 62.1 & 74.7 & 82.2 & 86 & 87.3 & 71.3 \\
\hline $\begin{array}{l}\text { Social } \\
\text { support }\end{array}$ & 69.8 & 86.12 & 56.11 & 33.2 & 69.8 & 81.5 & 75.7 & 81 & 81.4 & 72.4 \\
\hline $\begin{array}{l}\text { School } \\
\text { behavior }\end{array}$ & 70.3 & 84.37 & 83.85 & 86.3 & 90.7 & 83.3 & 91.3 & 92 & 91.5 & 90.3 \\
\hline $\begin{array}{l}\text { Perception of } \\
\text { health }\end{array}$ & 55.2 & 67.16 & 61.67 & 52.8 & 58.9 & 69.2 & 79.6 & 66.9 & 62.5 & 65.8 \\
\hline Total & 63.38 & 70.55 & 60.14 & 65.6 & 66.49 & 69.9 & 81.9 & 78.075 & 79 & 67.67 \\
\hline Q0LIE-AD-48: quality & of life impact in epile & osy adolescents. & & & & & & & 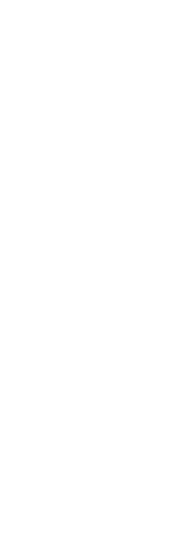 & \\
\hline
\end{tabular}


the utilized medications are more present in comparison to those of the subjacent illness ${ }^{38,39}$.

In our study, reports show that approximately a third of the participants are found to be under a polytherapy regime; nevertheless, only $22.2 \%$ presented an adequate control of convulsive events. On the contrary, participants with monotherapy had proper control of their seizures in $75 \%$ of cases. This may come as a result of the fact that monotherapy facilitates adherence to treatment ${ }^{40}$.

\section{Memory and learning}

Most children and adolescents (70\%) report problems with memory and/or other learning aspects. Young people do not feel physically or mentally capable of learning. Therefore, continuous learning is essential. Seizures and postictal periods often produce transitory memory problems. Some patients comment that a short seizure, in the context of a school day, would erase their memory for the day ${ }^{41}$.

\section{Attitude toward epilepsy}

This domain appears in all studies as the area with the lowest score; similar data were obtained in the studied sample. Despite this, the result is above the studies by Benavente-Aguilar (35.6 and 34.7, respectively $)^{9,10}$, Cramer et al. (39.8) ${ }^{25}$, Barbosa et al. $(39.8)^{19}$, Zamani et al. $(22.5)^{16}$, and Wang et al. (24.1) ${ }^{20}$. The low scores of this domain may reflect the poor understanding of seizures and/or epilepsy, which could significantly affect HRQoL perception and daily functioning'. Therefore, the most positive attitudes can be generated by a better understanding of the disease.

\section{Physical functioning}

In this study, the physical functioning domain, defined by activities such as playing, exercise and domestic chores, was scored within parameters in $76.3 \%$ of participants, with a score of 67.57 , data only compared to those results obtained by Cramer et al. ${ }^{25}$ (63.6); the rest of the reports have better scores. It is worth noting that in this domain, females were the most affected.

\section{Stigma}

The stigma linked to epilepsy is common, though it varies between cultures. At present, studies worldwide show improvement in public attitudes toward epilepsy, yet "old ideas" remain an influence in popular concepts of epilepsy, which results in continuous errors of perception and negative attitudes ${ }^{41}$. These negative attitudes may generate low self-esteem, alterations in independence, bad relationships, anxiety, depression, and difficulty in education and business, as well as social discrimination in people with epilepsy who experience the stigma due to their base diagnosis ${ }^{21,42}$.

The studied population showed that only $23 \%$ of participants had a low score for this domain, yet, in comparison to the rest of the domains, it remained above average. In the literature, most analyzed studies show adequate scores for this subscale, the lowest scores being from China and Iran ${ }^{12,15,16,20}$. Previous data indicated that there was a considerable cultural variation between our country and the rest of the world.

Stigma and discrimination are linked to a loss of identity and the threat imposed by the inability to perform normally in social roles ${ }^{39}$. Ethnographic studies of local communities in China also found that people with epilepsy are considered of low social value, and thus face significant rejection ${ }^{12}$.

\section{Social support}

Social support refers to the exchanges of emotional and instrumental resources between an individual and his/her social environment, destined to improve the individual's health. It can also be conceived as a resource which contributes to improving a patient's QoL ${ }^{42}$.

The average score for this subscale in our study was 69.8, a score below most countries, yet higher than those of China and Iran ${ }^{12,15,16}$. This variation in results is caused mainly due to cultural traits; an example of these is Asian countries, where patients with epilepsy are described as the target of prejudicial behavior ${ }^{6}$. In China, as in most developing countries, predominant cultural attitudes stigmatize people with epilepsy ${ }^{12,40}$. In a study conducted by Elliott et al. ${ }^{41}$ in Toronto, children, and adolescents with refractory epilepsy discuss aspects related to the quality and quantity of their social interactions with their relatives and friends.

\section{Behavior at school}

This subscale presented an average of 70.35 , which within the domains remain in an intermediate position; however, it is one of the domains with the highest percentage of affected participants (53\%). When comparing this score with other countries, our population falls under the rest. The highest scores were obtained in a 
study conducted by Stevanovic ${ }^{17,18}$ in Serbia (93.57 and 91.3, respectively).

\section{Perception of health}

This area is characterized by being one of the lowest scores compared to the rest of the subscales; moreover, when compared to results from other countries, where the scores were between 61.67 and 81.42; we can observe that it remains an adjacent score. Females predominate this area with partial control of seizures.

\section{Conclusions}

Based on the application of the QOLIE-AD-48 questionnaire, it was concluded that, despite adequate control of crises, HRQoL in patients between 12 and 17 years of age is regular. This suggests that it is not only the seizures and the number of them that affect the external environment of adolescents but also that there are other factors which may modify the patient's integral well-being.

We were able to observe that, within the female group, the specific areas of "perception of health" and "impact of epilepsy" are usually the most affected. On the contrary, in males, we were able to observe that the domains "physical functioning" and "perception of health" are those which contribute most to the alterations in their QoL and, subsequently, in their "behavior at school."

This makes us continue with the constant effort against stigmatization of patients with epilepsy, which as we can see in both areas "social support" and "social behavior" are directly influenced, and this determinately affects the evolution of our patients in the alterations in their social and gathering circles, which in many occasions forces them to perform different activities to those of a child without epilepsy, or in some cases they are treated differently during the same school activities. Great communication is necessary not only with the patient but with the most influenceable people in their surroundings so that he/she can reinforce trust, lower anxiety levels and develop a life with normal characteristics.

\section{Ethical disclosures}

Protection of human and animal subjects. The authors declare that the procedures followed were in accordance with the regulations of the relevant clinical research ethics committee and with those of the Code of Ethics of the World Medical Association (Declaration of Helsinki).

Confidentiality of data. The authors declare that they have followed the protocols of their work center on the publication of patient data.

Right to privacy and informed consent. The authors have obtained the written informed consent of the patients or subjects mentioned in the article. The corresponding author is in possession of this document.

\section{References}

1. Wheless JW, Kim HL. Adolescent seizures and epilepsy syndromes. Epilepsia. 2002;43 Suppl 3:33-52.

2. Sbarra DA, Rimm-Kaufman SE, Pianta RC. The behavioral and emotional correlates of epilepsy in adolescence: a 7-year follow-up study. Epilepsy Behav. 2002;3:358-67.

3. McEwan MJ, Espie CA, Metcalfe J. A systematic review of the contribution of qualitative research to the study of quality of life in children and adolescents with epilepsy. Seizure. 2004;13:3-14.

4. WHOQOL Group. The world health organization quality of life assessment (WHOQOL): position paper from the world health organization. Soc Sci Med. 1995;41:1403-9.

5. Valdivia-Álvarez I, Abadal-Borges G. Epilepsia de difícil control en pediatría: Nuevas drogas antiepilépticas. Rev Cubana Pediatr. 2005;77: 3-4.

6. Velarde-Jurado E, Avila-Figueroa C. Evaluación de la calidad de vida. Salud Pública Méx. 2002;44:349-61.

7. López-Rojas V, Barragán-Pérez $E$, Hernández-Hernández $M$, Watemberg N, Legido S. Calidad de vida en pacientes adolescentes con epilepsia en México. Rev Med Hondur. 2010;78:179-82.

8. Quality of Life in Epilepsy QOLIE-31 (Version 1.0). RAND. Santa Mónica, California. Copyright; 1993. Available from: https://www.epilepsy.com/sites/ core/files/atoms/files/QOLIE-31\%20for\%20web-USA.pdf. [Last accessed on 2019 Feb 26].

9. Benavente-Aguilar I, Morales-Blánquez C, Rubio-Calvo EA. Adaptación transcultural del cuestionario de medida de calidad de vida (QOLIE-AD-48) en adolescentes epilépticos. Psiquis (Madr). 2002;226-37.

10. Benavente-Aguilar I, Morales-Blánquez C, Rubio EA, Rey JM. Quality of life of adolescents suffering from epilepsy living in the community. J Paediatr Child Health. 2004;40:110-3.

11. Jadhav PM, Bodke NK, Sanap DA, Gogtay NJ. Assessment and comparison of health-related quality-of-life (HRQOL) in patients with epilepsy in India. Epilepsy Behav. 2013;27:165-8.

12. Wu DY, Ding D, Wang Y, Hong Z. Quality of life and related factors in Chinese adolescents with active epilepsy. Epilepsy Res. 2010;90:16-20.

13. Montanaro M, Battistella PA, Boniver C, Galeone D. Quality of life in young Italian patients with epilepsy. Neurol Sci. 2004;25:264-73.

14. Siqueira NF, Oliveira FL, Siqueira JA, de Souza EA. Quality of life in epilepsy: a study of Brazilian adolescents. PLoS One. 2014;9:e106879.

15. Zamani G, Mehdizadeh M, Sadeghi P. Attempt to suicide in young ages with epilepsy. Iran J Pediatr. 2012;22:404-7.

16. Zamani G, Shiva S, Mohammadi M, Mahmoudi Gharaie J, Rezaei N. A survey of quality of life in adolescents with epilepsy in Iran. Epilepsy Behav. 2014;33:69-72.

17. Stevanovic D. Health-related quality of life in adolescents with well-controlled epilepsy. Epilepsy Behav. 2007;10:571-5.

18. Stevanovic D, Lozanovic-Miladinovic D, Jovic N, Sarenac M. The Serbian QOLIE-AD-48: translation, cultural adaptation, and preliminary psychometric evaluation. Epilepsy Behav. 2005;7:240-5.

19. Barbosa FD, Guerreiro MM, de Souza EA. The brazilian version of the quality of life in epilepsy inventory for adolescents: translation, validity, and reliability. Epilepsy Behav. 2008;13:218-22.

20. Wang M, Wu L, Zheng Y, Zhang Q, Li C. The Chinese QOLIE-AD-48: translation, validity, and reliability. Epilepsy Behav. 2009;14:476-80.

21. Devinsky O, Westbrook L, Cramer J, Glassman M, Perrine K, Camfield C, et al. Risk factors for poor health-related quality of life in adolescents with epilepsy. Epilepsia. 1999;40:1715-20.

22. Cross $\mathrm{JH}$. Epilepsy in the WHO European region: fostering epilepsy care in Europe. Epilepsia. 2011;52:187-8.

23. Kwan P, Sander JW. The natural history of epilepsy: an epidemiological view. J Neurol Neurosurg Psychiatry. 2004;75:1376-81.

24. Austin JK, Huster GA, Dunn DW, Risinger MW. Adolescents with active or inactive epilepsy or asthma: a comparison of quality of life. Epilepsia. 1996;37:1228-38. 
25. Cramer JA, Westbrook LE, Devinsky O, Perrine K, Glassman MB, Camfield $C$, et al. Development of the quality of life in epilepsy inventory for adolescents: the QOLIE-AD-48. Epilepsia. 1999;40:1114-21.

26. Farwell JR, Lee YJ, Hirtz DG, Sulzbacher SI, Ellenberg JH, Nelson KB et al. Phenobarbital for febrile seizures effects on intelligence and on seizure recurrence. N Engl J Med. 1990;322:364-9.

27. Delgado RP, Hidalgo ML, Pisón JL, Torres BS, Claveras ST, Jiménez MG Epilepsia de inicio entre el mes y los tres meses de vida: nuestra experiencia de 11 años. Neurología. 2010;25:90-5.

28. Jackson DC, Dabbs K, Walker NM, Jones JE, Hsu DA, Stafstrom CE, et al. The neuropsychological and academic substrate of new/recent-onset epilepsies. J Pediatr. 2013;162:1047-530.

29. Talero-Gutiérrez C, Sánchez-Torres JM, Velez-van-Meerbeke A. Aptitudes de aprendizaje y desempeño escolar en niños y jóvenes con epilepsia ausencia. Neurología. 2015;30:71-6.

30. Battistini MC, La Briola F, Menini S, Lenti C. Specific learning disorde in the primary epilepsies of childhood. Minerva Pediatr. 2010;62:559-63.

31. Acosta M.T. Neurodesarrollo: Integración de las Perspectivas Neurológica y Neuropsicológica. Trastornos del Neurodesarrollo y Aprendizaje. Bogotá: Hospital Militar Central; 1999. p. 13-35.

32. Lennox WG. Brain injury, drugs, and environment as causes of mental decay in epilepsy. Am J Psychiatry. 1942;99:174-80.

33. Mulas F, Hernández S, Mattos L, Abad-Mas L, Etchepareborda MC Dificultades del aprendizaje en los niños epilépticos. Rev Neurol. 2006; 42Supl 2:S157-62.

34. Oostrom KJ, Smeets-Schouten A, Kruitwagen CL, Peters AC, Jennekens-Schinkel A, Dutch Study Group of Epilepsy in Childhood. et al. No only a matter of epilepsy: early problems of cognition and behavior in children with "epilepsy only" a prospective, longitudinal, controlled study starting at diagnosis. Pediatrics. 2003;112:1338-44.

35. Pascual-Pascual SI. Características clínicas de las epilepsias del adolescente. Rev Neurol. 1999;28:36-43.

36. Cockerell OC, Johnson AL, Sander JW, Shorvon SD. Prognosis of epilepsy: a review and further analysis of the first nine years of the British national general practice study of epilepsy, a prospective population-based study. Epilepsia. 1997;38:31-46.

37. Wilfong AA. Monotherapy in children and infants. Neurology. 2007; 69 (24 Suppl 3):S17-22.

38. Turky A, Beavis JM, Thapar AK, Kerr MP. Psychopathology in children and adolescents with epilepsy: an investigation of predictive variables. Epilepsy Behav. 2008;12:136-44.

39. Baker GA, Hargis $\mathrm{E}$, Hsih MM, Mounfield $\mathrm{H}$, Arzimanoglou A, Glauser $\mathrm{T}$, et al. Perceived impact of epilepsy in teenagers and young adults: an international survey. Epilepsy Behav. 2008;12:395-401.

40. Perrine K, Hermann BP, Meador KJ, Vickrey BG, Cramer JA, Hays RD, et al. The relationship of neuropsychological functioning to quality of life in epilepsy. Arch Neurol. 1995;52:997-1003.

41. Elliott IM, Lach L, Smith ML. I just want to be normal: a qualitative study exploring how children and adolescents view the impact of intractable epilepsy on their quality of life. Epilepsy Behav. 2005;7:664-78.

42. Choi-Kwon $\mathrm{S}$, Chung $\mathrm{C}$, Kim $\mathrm{H}$, Lee $\mathrm{S}$, Yoon $\mathrm{S}$, Kho $\mathrm{H}$, et al. Factors affecting the quality of life in patients with epilepsy in Seoul, South Korea. Acta Neurol Scand. 2003;108:428-34 